\title{
Usefulness of ECG criteria to rule out left ventricular hypertrophy in older individuals with true left bundle branch block: an observational study
}

Caio Assis Moura Tavares ${ }^{1}$, Nelson Samesima ${ }^{3}$, Felippe Lazar Neto' ${ }^{1}$, Ludhmila Abrahão Hajjar', Lucas C. Godoy ${ }^{1,2}$, Eduardo Messias Hirano Padrão ${ }^{1}$, Mirella Facinn', Wilson Jacob Filho', Michael E. Farkouh ${ }^{2}$ and Carlos Alberto Pastore ${ }^{1,3^{*}}$

\begin{abstract}
Background: Advanced age is associated with both left bundle branch block (LBBB) and hypertension and the usefulness of ECG criteria to detect left ventricular hypertrophy $(\mathrm{LVH})$ in patients with $L B B B$ is still unclear. The diagnostic performance and clinical applicability of ECG-based LVH criteria in patients with LBBB defined by stricter ECG criteria is unknown. The aim of this study was to compare diagnostic accuracy and clinical utility of ECG criteria in patients with advanced age and strict LBBB criteria.

Methods: Retrospective single-center study conducted from Jan/2017 to Mar/2018. Patients undergoing both ECG and echocardiogram examinations were included. Ten criteria for ECG-based LVH were compared using LVH defined by the echocardiogram as the gold standard. Sensitivity, specificity, predictive values, likelihood ratios, AUC, and the Brier score were used to compare diagnostic performance and a decision curve analysis was performed.

Results: From 4621 screened patients, 68 were included, median age was 78.4 years, (IQR 73.3-83.4), 73.5\% with hypertension. All ECG criteria failed to provide accurate discrimination of LVH with AUC range between 0.54 and 0.67 , and no ECG criteria had a balanced tradeoff between sensitivity and specificity. No ECG criteria consistently improved the net benefit compared to the strategy of performing routine echocardiogram in all patients in the decision curve analysis within the 10-60\% probability threshold range.
\end{abstract}

Conclusion: ECG-based criteria for LVH in patients with advanced age and true LBBB lack diagnostic accuracy or clinical usefulness and should not be routinely assessed.

Keywords: Hypertension, Electrocardiography, Left bundle branch block, Elderly

*Correspondence: ecg_pastore@incor.usp.br

${ }^{1}$ Instituto do Coracao (InCor), Hospital das Clinicas HCFMUSP, Faculdade

de Medicina, Universidade de Sao Paulo, Sao Paulo, Brazil

Full list of author information is available at the end of the article

\begin{abstract}
Introduction
Left ventricular hypertrophy (LVH) is an ultimate consequence of long-standing hypertension and is associated with all-cause mortality [1]. In patients receiving antihypertensive therapy, the improvement of $\mathrm{LVH}$, as evaluated by the electrocardiogram (ECG), is associated with improved cardiovascular prognosis [2, 3]. Accordingly, current clinical practice guidelines recommend using the
\end{abstract}

(c) The Author(s) 2021. Open Access This article is licensed under a Creative Commons Attribution 4.0 International License, which permits use, sharing, adaptation, distribution and reproduction in any medium or format, as long as you give appropriate credit to the original author(s) and the source, provide a link to the Creative Commons licence, and indicate if changes were made. The images or other third party material in this article are included in the article's Creative Commons licence, unless indicated otherwise in a credit line to the material. If material is not included in the article's Creative Commons licence and your intended use is not permitted by statutory regulation or exceeds the permitted use, you will need to obtain permission directly from the copyright holder. To view a copy of this licence, visit http://creativecommons.org/licenses/by/4.0/. The Creative Commons Public Domain Dedication waiver (http://creativeco mmons.org/publicdomain/zero/1.0/) applies to the data made available in this article, unless otherwise stated in a credit line to the data. 
ECG as part of the routine assessment of patients with hypertension at baseline and during follow-up [4].

Abnormal depolarization of the left ventricle due to left bundle branch block (LBBB) may compromise the electrocardiographic diagnose of LVH because the LVH diagnostic criteria were developed and validated in patients without conduction disturbances [5]. More recent studies that evaluated ECG diagnostic performance in patients with LBBB, were heterogeneous and had a wide range of sensitivities due to the inclusion of different populations, use of multiple cut-offs, and distinct criteria [6], creating barriers for implementation into clinical practice. In fact, some authors even consider that the electrocardiographic diagnosis of LVH should not be applied in those with LBBB [7]. The lack of universally accepted standards to distinguish true LBBB from conduction delay [8] adds even more complexity to this topic.

Advanced age is associated with hypertension and LBBB [9-11], and the number of patients with both conditions is expected to grow progressively in the next years because of the overall aging population. Validating or developing new accurate ECG criteria for LVH in this population can have relevant and immediate clinical applicability. We aim to evaluate the diagnostic accuracy of the traditional ECG-based LVH criteria in patients with $\mathrm{LBBB}$ and the clinical usefulness of using a selective strategy to guide echocardiogram orders.

\section{Methods}

\section{Population}

We retrospectively collected data from patients $\geq 70$ years old (as of March/31/2018) evaluated at a tertiary care teaching hospital in Sao Paulo, Brazil. From January/2017 to March/2018, all outpatients and inpatients in non-critical care units patients who underwent a 12-lead ECG and echocardiogram from January/2017 to $M a r c h / 2018$ were deemed eligible. Exclusion criteria were time between ECG and echocardiogram greater than 180 days, ECG images that could not be retrieved, only ECG images available from the ICU and ECG with lead changes or missing leads. ECG tracings were then inspected to exclude patients with ventricular pacemaker, non-sinus rhythm, advanced atrioventricular block or QRS with non-LBBB morphology (Fig. 1).

\section{ECG analysis}

Standard 12-lead ECGs were acquired at $10 \mathrm{~mm} / \mathrm{mV}$ calibration and speed of $25 \mathrm{~mm} / \mathrm{s}$. Two physicians (CAMT and EMP) independently screened all tracings for LBBB, using the strict definition proposed by Strauss et al. (available in the Additional file 1: Table S1). As the LBBB identified by the ECG can represent conduction disease, left ventricle myocardial disease or a combination of both, the stricter LBBB criteria proposed by Strauss identify only those with true conduction disease and were developed aiming to predict who would better respond to cardiac resynchronization therapy (CRT) [12]. In cases of discordance between the examiners, the tracings were reviewed together with an experienced cardiologist (CAP) and the classification was defined based on consensus. Two cardiologists (NS and MF), blinded to echocardiogram and clinical data, calculated the following LVH criteria in all ECGs with LBBB: PegueroLo Presti, Cornell voltage, Cornell Voltage duration, SV2 plus SV3, $R$ wave in avL, $R$ wave product in avL, Sokolow-Lyon, Sokolow-Lyon product, Dalfó criteria and Gubner-Ungerleider (Additional file 1: Table S2). In case of discordances, a third cardiologist also revised the ECG tracings (CAMT).

\section{Echocardiographic analysis}

Echocardiograms were used as the gold-standard method to diagnose LVH. All echocardiograms were performed at our institution according to international guidelines [12]. Left Ventricular Mass was calculated using the Devereux formula: left ventricular mass $(\mathrm{g})=0,80 \times 1,04$ [(septal thickness + internal diameter + posterior wall thick-

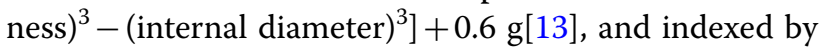
the Body Surface Area (BSA), calculated by the Dubois Formula $\quad\left(B S A=0.007184 \times\right.$ height $\quad(m)^{0.725} \times$ weight $(\mathrm{kg})^{0.425}$, with $\mathrm{LVH}$ defined as $>95 \mathrm{~g} / \mathrm{m}^{2}$ in females and $>115 \mathrm{~g} / \mathrm{m}^{2}$ male subjects.

\section{Clinical data}

Epidemiological data from all patients were retrieved from the electronic medical record: anthropometric data (height, weight, body mass index), age in years (at the day of echocardiogram exam), comorbidities as diagnosed by the attending physician (hypertension, diabetes, coronary artery disease, prior myocardial infarction, coronary artery bypass graft surgery, prior percutaneous coronary intervention, atrial fibrillation, peripheral artery disease, chronic obstructive pulmonary disease), medications prescribed (beta-blockers, calcium channel blockers, diuretics, angiotensin-converting enzyme inhibitors (ACEi), angiotensin II receptors blockers (ARB), hydralazine/ nitrate). Vital signs were obtained through chart review (blood pressure and heart rate).

\section{Statistical analysis}

Clinical and echocardiographic characteristics were summarized as median and interquartile range or proportions, based on LVH status in the echocardiogram. The rank sum test was used for comparing continuous variables between groups and the Fisher exact test for categorical variables. For each ECG criterion, sensitivity, 
4621 patients evaluated at our institution between Jan/2017 and Mar/2018

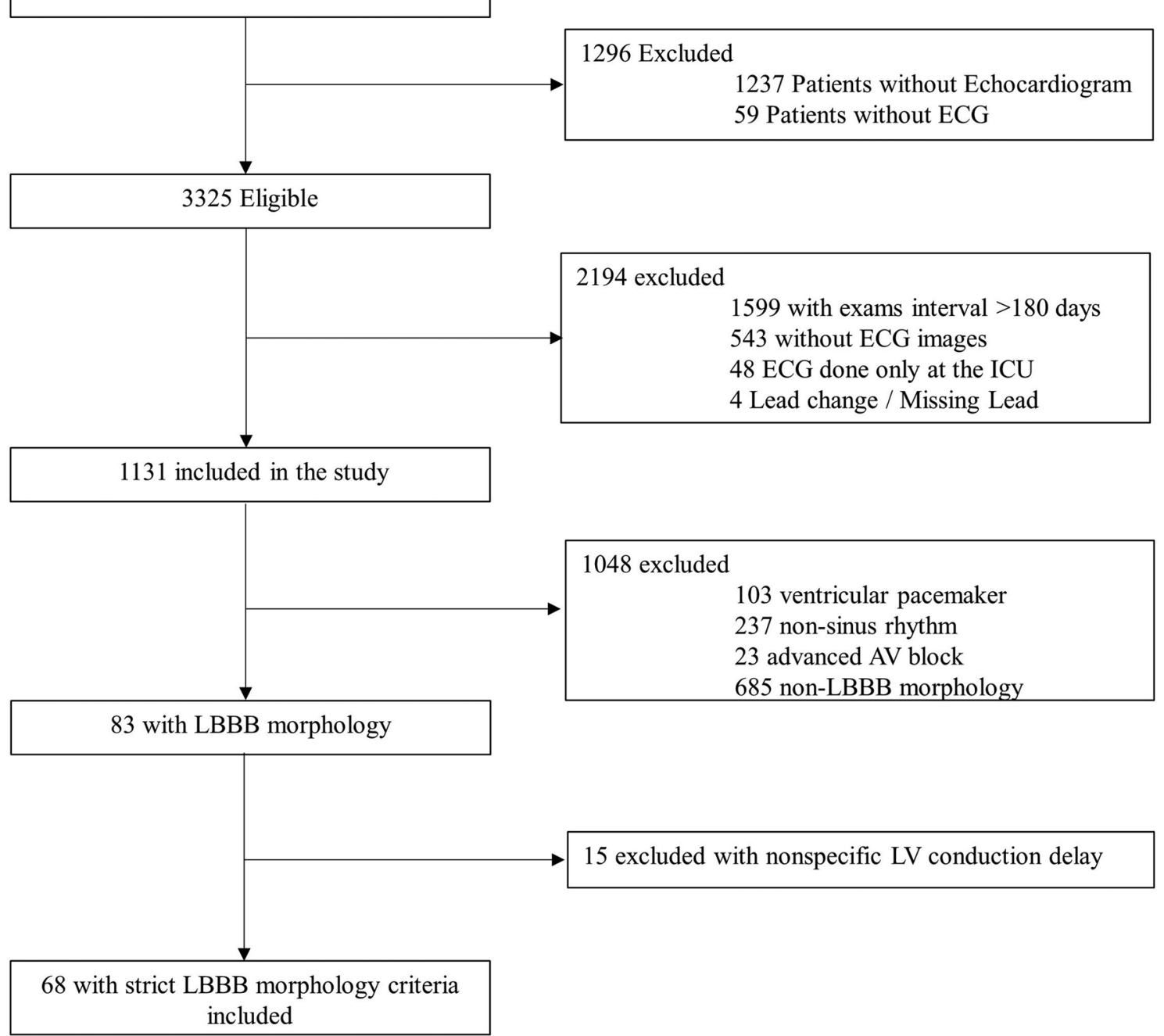

Fig. 1 Study flowchart. AV=atrioventricular; ECG = electrocardiography; ICU = Intensive Care Unit; LBBB= Left Bundle Branch Block

specificity, positive and negative predictive values, and likelihood ratios were calculated using the echocardiogram as the gold standard. Pearson correlation coefficients between ECG criteria and left ventricular mass index were calculated using the ECG criteria as continuous variables. Discriminative performance of the ECG criteria was calculated according to the area under the curve (AUC) of the receiver operating characteristic (ROC) curve. The Brier Score was calculated as a measure of overall performance, defined as the mean squared difference between the observed (Echo-LVH) and predicted outcome (ECG-LVH, for each ECG criteria). The Brier Score ranges from 0 to 1 with lower values being indicative of better overall performance.
We used a decision curve analysis framework to assess how each ECG criterion would impact clinical practice. In brief, the net-benefit for each ECG criterion was calculated by subtracting the proportion of false positives from the true positives, weighted by the relative harm of a false positive and a false negative result. Each score was then compared to strategies of ordering echocardiogram for all or none, by subtracting the estimated net-benefit of ordering-all strategy from the respective criteria. This method considers how many false positives cases the physician is willing to treat to avoid not treating a false negative patient. In our case, this can be translated as how many echocardiograms without LVH the physician is willing to accept to avoid not recognizing one 
echocardiogram with LVH, which could guide the physician's decision on echocardiogram orders. The threshold probabilities were selected a priori with a large threshold range (0.1-0.6) to mirror different resource settings. Detailed explanation of the decision curve analysis can be found elsewhere [13]. Our manuscript was based in the 2015 Standards for Reporting Diagnostic Accuracy Studies (STARD), available in the Additional file 1: Table S3. A two-sided $p<0.05$ was considered statistically significant. Statistical analysis was performed using the R software, version 3.6.2 (R Project for Statistical Computing).

\section{Results}

\section{Characteristics of the study population}

As outlined in Fig. 1, after screening 4621 patients, 68 patients with LBBB criteria were included, of whom 46 (67.6\%) had LVH based on the echocardiogram. The median age was 78.4 years (IQR 73.3-83.4), most were female $(\mathrm{n}=38,55.9 \%)$, and hypertension was the most common chronic disease $(n=50,73.5 \%)$; followed by coronary artery disease $(\mathrm{n}=32,47.1 \%)$ and dyslipidemia $(\mathrm{n}=27,39.7 \%)$. The median time interval between the ECG and the echocardiogram was 14 days (IQR 1.043.3). Patients with LVH were older and predominantly male. Demographic data of the population is summarized in Table 1. As expected, echocardiographic diagnosis of $\mathrm{LVH}$ was associated with distinct echocardiographic parameters: lower ejection fraction (46.5\% versus $59.5 \%$, $p=0.027)$, higher left ventricular mass index (141.0 versus $97.5 \mathrm{~g} / \mathrm{m}^{2}, p<0.001$ ), increased left atrium diameter ( 46.0 versus $38.0 \mathrm{~mm}, p<0.001$ ), left ventricular end-diastolic diameter (57.5 versus $48.0 \mathrm{~mm}, p=0.001$ ), and left ventricular end-systolic diameter $(43.5$ versus $34.0 \mathrm{~mm}$, $p=0.004)$, as shown in Table 2 .

\section{Diagnostic performance of the ECG criteria}

Sensitivity, specificity, predictive values and likelihood ratios The standard cut-offs of the ECG criteria had a wide range of sensitivities (26.1-100\%) and specificities (0-81.8\%) (Table 3). No single ECG criterion had a

Table 1 Demographic data

\begin{tabular}{|c|c|c|c|c|}
\hline Demographic data & $\begin{array}{l}\text { All patients } \\
(n=68)\end{array}$ & $\begin{array}{l}\text { LVH patients } \\
(n=46)\end{array}$ & $\begin{array}{l}\text { Non-LVH patients } \\
(n=22)\end{array}$ & $P$ value \\
\hline Age (years) & $78.4(73.3-83.4)$ & $78.7(74.5-79.9)$ & $76.2(71.6-80.6)$ & 0.018 \\
\hline Female & $38(55.9 \%)$ & $19(41.3 \%)$ & $19(86.4 \%)$ & $<0.001$ \\
\hline $\mathrm{BMI}\left(\mathrm{kg} / \mathrm{m}^{2}\right)$ & $25.3(23-8-27.8)$ & $24.8(22.9-27.7)$ & $26.0(24.2-27.7)$ & 0.235 \\
\hline $\mathrm{SBP}(\mathrm{mmHg})$ & $120.0(110.0-140.0)$ & $120.0(110.0-132.0)$ & $121.0(112.5-140.0)$ & 0.256 \\
\hline $\mathrm{DBP}(\mathrm{mmHg})$ & $71.5(60.0-80.0)$ & $70.0(60.0-80.0)$ & $80.0(71.5-80.0)$ & 0.033 \\
\hline Heart rate (bpm) & $67.0(57.0-77.0)$ & $69.0(55.5-77.8)$ & $65.0(59.0-73.8)$ & 0.854 \\
\hline Hypertension & $50(73.5 \%)$ & $33(71.7 \%)$ & $17(77.3 \%)$ & 0.772 \\
\hline Type 2 diabetes & $19(27.9 \%)$ & $10(21.7 \%)$ & $9(40.9 \%)$ & 0.148 \\
\hline Dyslipidemia & $27(39.7 \%)$ & $18(39.1 \%)$ & $9(40.9 \%)$ & 1.000 \\
\hline Paroxysmal atrial fibrillation & $11(16.2 \%)$ & $9(19.6 \%)$ & $2(9.1 \%)$ & 0.482 \\
\hline Coronary artery disease & $32(47.1 \%)$ & $19(41.3 \%)$ & $13(59.1 \%)$ & 0.201 \\
\hline Previous myocardial infarction & $17(25.0 \%)$ & $11(23.9 \%)$ & $6(27.3 \%)$ & 0.772 \\
\hline Previous CABG & $14(20.6 \%)$ & $7(15.2 \%)$ & $7(31.8 \%)$ & 0.198 \\
\hline Previous $\mathrm{PCl}$ & $18(26.5 \%)$ & $12(26.1 \%)$ & $6(27.3 \%)$ & 1.000 \\
\hline Peripheral artery disease & $6(8.8 \%)$ & $4(8.7 \%)$ & $2(9.1 \%)$ & 1.000 \\
\hline Chronic obstructive pulmonary disease & $8(11.8 \%)$ & $6(13.0 \%)$ & $2(9.1 \%)$ & 1.000 \\
\hline \multicolumn{5}{|l|}{ Medication use } \\
\hline ACEi & $31(45.6 \%)$ & $20(43.5 \%)$ & $11(50.0 \%)$ & 0.795 \\
\hline ARBs & $19(27.9 \%)$ & $13(28.3 \%)$ & $6(27.3 \%)$ & 1.000 \\
\hline CCBs & $14(20.6 \%)$ & $8(17.4 \%)$ & $6(27.3 \%)$ & 0.356 \\
\hline Beta blocker & 47 (69.1\%) & $33(71.7 \%)$ & $14(63.76 \%)$ & 0.579 \\
\hline Hydralazine/Nitrate & $11(16.2 \%)$ & $8(17.4 \%)$ & $3(13.6 \%)$ & 1.000 \\
\hline Diuretic & $44(64.7 \%)$ & $28(60.9 \%)$ & $16(72.7 \%)$ & 0.421 \\
\hline Days between echocardiogram and ECG & $14(1.0-43.3)$ & $13.5(1.0-42.8)$ & $14(3.3-47.8)$ & 0.506 \\
\hline
\end{tabular}

Demographic data of the cohort, according to the left ventricular hypertrophy status evaluated by echocardiography. Values are median and interquartile range or $n$ (\%)

ACEi: = Angiotensin-Converting Enzyme inhibitors; ARBs = Angiotensin Receptor blockers; BMI = Body Mass Index; $C A B G=$ Coronary Artery Bypass Graft; $\mathrm{CCBs}=$ Calcium Channel Blockers; $\mathrm{DBP}=$ Diastolic Blood Pressure; $\mathrm{PCl}=$ Percutaneous Coronary Intervention; $\mathrm{SBP}=\mathrm{Systolic}$ Blood Pressure 
Table 2 Echocardiographic parameters

\begin{tabular}{|c|c|c|c|}
\hline Echocardiographic parameters & $\begin{array}{l}\text { LVH patients } \\
(n=46)\end{array}$ & $\begin{array}{l}\text { Non-LVH patients } \\
(n=22)\end{array}$ & $P$ value \\
\hline Ejection fraction (\%) & $46.5(30.0-60.8)$ & $59.5(40.3-65.8)$ & 0.027 \\
\hline Left ventricular mass index $\left(\mathrm{g} / \mathrm{m}^{2}\right)$ & $141.0(117.8-173.5)$ & $97.5(86.5-108.5)$ & $<0.001$ \\
\hline Relative wall thickness (no unit) & $0.37(0.30-0.44)$ & $0.41(0.33-0.45)$ & $<0.306$ \\
\hline Left Atrium diameter (mm) & $46.0(42.0-49.0)$ & $38.0(36.0-43.0)$ & $<0.001$ \\
\hline Interventricular septal diameter $(\mathrm{mm})$ & $10.5(9.3-10.7)$ & $10.0(9.0-11.0)$ & 0.085 \\
\hline Posterior wall diameter (mm) & $10.0(9.0-11.0)$ & $10.0(9.0-10.0)$ & 0.088 \\
\hline Left ventricular end- diastolic diameter (mm) & $57.5(50.0-65.8)$ & $48.0(47.0-55.8)$ & 0.001 \\
\hline Left ventricular end-systolic diameter (mm) & $43.5(33.8-55.5)$ & $34.0(31.3-37.8)$ & 0.004 \\
\hline Moderate or severe aortic stenosis & $9(19.6 \%)$ & $2(9.1 \%)$ & 0.482 \\
\hline Moderate or severe mitral regurgitation & $11(23.9 \%)$ & $1(4.5 \%)$ & 0.086 \\
\hline Moderate or severe aortic regurgitation & $4(8.7 \%)$ & $1(4.5 \%)$ & 1.000 \\
\hline
\end{tabular}

Echocardiographic parameters of cohort, according to the left ventricular hypertrophy status evaluated by echocardiography. Values are median and interquartile range or $\mathrm{n}(\%)$

Table 3 Clinical utility of the ECG criteria

\begin{tabular}{|c|c|c|c|c|c|c|}
\hline ECG criteria & $\begin{array}{l}\text { Sensitivity (\%) } \\
(95 \% \mathrm{Cl})\end{array}$ & $\begin{array}{l}\text { Specificity (\%) } \\
(95 \% \mathrm{Cl})\end{array}$ & $\begin{array}{l}\text { PPV (\%) } \\
(95 \% \mathrm{Cl})\end{array}$ & $\begin{array}{l}\text { LR+ } \\
(95 \% \mathrm{Cl})\end{array}$ & $\begin{array}{l}\text { NPV (\%) } \\
(95 \% \mathrm{Cl})\end{array}$ & $\begin{array}{l}\text { LR- } \\
(95 \% \mathrm{Cl})\end{array}$ \\
\hline Peguero-Lo Presti & $96.0(88.6-100)$ & $9.1(0-22.7)$ & $68.8(57.2-79.0)$ & $1.05(0.93-1.24)$ & $50.0(0-100)$ & $0.48(0-1.86)$ \\
\hline Cornell voltage & $87.0(76.0-96.1)$ & $27.3(8.0-47.4)$ & $71.4(59.3-83.7)$ & $1.2(0.92-1.67)$ & $50.0(22.2-78.6)$ & $0.48(0.1-1.46)$ \\
\hline Cornell VDP & $100(\mathrm{NA})$ & $9.1(0-22.2)$ & $69.7(58.2-80.0)$ & $1.10(1.00-1.28)$ & $100(\mathrm{NA})$ & $0(N A)$ \\
\hline $\mathrm{SV} 2+\mathrm{SV} 3$ & $39.1(26.1-53.8)$ & $59.1(36.9-79.2)$ & $66.7(50.0-84.4)$ & $0.96(0.50-2.15)$ & $31.7(17.5-46.5)$ & $1.03(0.70-1.70)$ \\
\hline RaVL & $26.1(13.3-38.7)$ & $81.8(63.2-95.7)$ & $75.0(50.0-93.8)$ & $0.96(0.50-2.15)$ & $34.6(21.6-48.2)$ & $0.90(0.69-1.19)$ \\
\hline R aVL VDP & $67.4(53.2-80.0)$ & $54.6(33.3-76.2)$ & $75.6(61.1-88.4)$ & $1.48(0.92-2.69)$ & $44.4(26.1-65.2)$ & $0.60(0.31-1.08)$ \\
\hline Sokolow-Lyon & $26.1(13.7-41.3)$ & $81.8(63.0-95.7)$ & $75.0(50.1-94.7)$ & $1.43(0.53-6.13)$ & $34.6(22.2-47.9)$ & $0.90(0.70-1.23)$ \\
\hline Sokolow-Lyon VDP & $60.9(46.5-73.5)$ & $50.0(29.2-71.4)$ & $71.8(56.4-85.4)$ & $1.22(0.73-2.18)$ & $37.9(20.7-54.6)$ & $0.78(0.46-1.40)$ \\
\hline Gubner-Ungerleider & $82.6(70.6-93.2)$ & $18.2(63.2-95.7)$ & $67.9(55.8-79.3$ & $1.01(0.79-1.32)$ & $33.3(6.7-62.5)$ & $0.96(0.32-4.24)$ \\
\hline Dalfó & $95.7(88.9-100)$ & $0(N A)$ & $66.7(55.9-78.5)$ & $0.96(0.89-1.00)$ & NA & NA \\
\hline
\end{tabular}

Diagnostic performance of all the ECG criteria in patients with left bundle branch block, using the echocardiogram based left ventricular hypertrophy as the goldstandard

$\mathrm{Cl}=$ Confidence Interval; $\mathrm{LR}+=$ positive likelihood ration; $\mathrm{LR}-=$ negative likelihood ratio; $\mathrm{NA}=$ non applicable; $\mathrm{NPV}=\mathrm{Negative} \mathrm{Predictive}$ Value; $\mathrm{PPV}=\mathrm{Positive}$ Predictive Value; $\mathrm{R} a \mathrm{VL}=\mathrm{R}$ wave in lead $\mathrm{aVL} ; \mathrm{SV} 2+\mathrm{SV} 3=$ sum of the $\mathrm{S}$ wave in $\mathrm{V} 2$ plus $\mathrm{V} 3 ; \mathrm{VDP}=$ voltage-duration product

good balance for both indices. The Peguero-Lo Presti and the Cornell Voltage Duration Product criteria had high sensitivity, but low specificity (sensitivity 100\%, specificity $9.1 \%$ and sensitivity $97.8 \%$, specificity $27.3 \%$, respectively), whereas the Sokolow-Lyon and R wave in lead avL criteria had high specificity but low sensitivity (specificity $81.8 \%$, sensitivity $26.1 \%$ and specificity $81.8 \%$, sensitivity $26.1 \%$, respectively). Nominally, the highest positive likelihood ratio was observed for $\mathrm{R}$ avL (1.48) and the lowest negative likelihood ratio for Cornell Voltage Duration Product. Overall, the $\mathrm{R}$ avL voltage duration product had the highest positive predictive value (75.6\%) and the Cornell Voltage Duration Product the highest negative predictive value (100\%).
Discriminative power assessed by the area under the curve (AUC) and overall performance according to the Brier score Discrimination of all ECG criteria was poor. The AUC ranged between 0.53 and 0.67 and the Brier score from 0.20 to 0.22 . The AUC of the Cornell Voltage duration product was numerically higher than the other criteria $(0.67,95 \%$ CI 0.53-0.79) (Table 4).

Correlation between ECG criteria and left ventricular mass index Moderate correlation (0.39-0.53) was observed for all ECG criteria. Figure 2 summarizes the correlation coefficients between the left ventricular mass index and ECG criteria.

Decision curve analysis For all the tested threshold probabilities $(10-60 \%)$ we found little to no clinical 
Table 4 Area under the receiver operating characteristic curve (AUC) and brier score for all ECG criteria

\begin{tabular}{lll}
\hline ECG criteria & AUC $(\mathbf{9 5} \% \mathbf{C l})$ & Brier score \\
\hline Peguero-Lo Presti & $0.59(0.45-0.72)$ & 0.21 \\
Cornell Voltage & $0.55(0.40-0.68)$ & 0.22 \\
Cornell VDP & $0.67(0.53-0.79)$ & 0.20 \\
SV2+SV3 & $0.53(0.38-0.68)$ & 0.22 \\
RaVL & $0.62(0.46-0.76)$ & 0.21 \\
RaVL VDP & $0.64(0.49-0.78)$ & 0.21 \\
Sokolow-Lyon & $0.54(0.39-0.69)$ & 0.22 \\
Sokolow-Lyon VDP & $0.57(0.42-0.72)$ & 0.22 \\
Gubner-Ungerleider & $0.54(0.42-0.72)$ & 0.22 \\
Dalfó & $0.55(0.39-0.69)$ & 0.22 \\
\hline
\end{tabular}

AUC and Brier Score for the ECG criteria using the echocardiogram based left ventricular hypertrophy as the gold-standard

$\mathrm{Cl}=$ Confidence Interval; $\mathrm{R}$ aVL $=\mathrm{R}$ wave in lead $\mathrm{aVL} ; \mathrm{SV} 2+\mathrm{SV} 3=$ sum of the $\mathrm{S}$ wave in $\mathrm{V} 2$ plus $\mathrm{V} 3 ; \mathrm{VDP}=$ voltage-duration product

benefit of utilizing ECG criteria compared to a strategy of ordering echocardiograms for all patients (Fig. 3).

\section{Discussion}

Our study had three main findings: first, the poor diagnostic performance of traditional ECG criteria in patients with strict criteria for LBBB; second, the low diagnostic accuracy of the recently proposed Peguero-Lo Presti criteria in patients with LBBB and third, the lack of clinical usefulness of the ECG criteria as a screening method for deciding on the need for an echocardiogram.

As expected, LBBB poises a challenging issue for ECG screening tests because it is associated with a high prevalence of $\mathrm{LVH}$ (over 40\% in the literature [14-16] and 68\% in our cohort). High pre-test probability of disease consequently demands a criterion to have an exceptionally low negative likelihood ratio to exclude the diagnosis. For instance, even though the Cornell Voltage Duration Product captured all patients with $\mathrm{LVH}$, with a sensitivity of $100 \%$, specificity was very low $(9.1 \%)$, nearly classifying every patient as with ECG-based LVH, thus not useful as tool to discriminate/identify those with $\mathrm{LVH}$. None of the other ECG scores and respective cut-offs tested had a negative predictive value (NPV) over $80 \%$ and therefore were unable to adequately rule-out $\mathrm{LVH}$. One could alter criteria cut-offs; however, the analysis of the decision curve showed little to no clinical benefit in using these scores even when accounting for a wide range of thresholds.

These results question the usefulness of the LVH electrocardiographic criteria in patient with LBBB. Although some reports have yielded high sensitivity [17-21], especially when using a computer-assisted diagnostic system [6], other groups have also questioned the use of
ECG-based LVH criteria in patients with LBBB [7]. Previous studies testing ECG-based LVH criteria in patients with LBBB were performed prior to the development of the stricter $\mathrm{LBBB}$ criteria, and likely enrolled a more heterogeneous population, mixing conduction disease with LVH or LV dilation. This limitation could have artificially improved the LVH diagnostic performance of the ECG.

Our highly selective approach identified a more homogenous group of patients with true conduction disease where ECG-based criteria were unsuitable to diagnose echocardiographic LVH. Because conventional LBBB criteria on the ECG represents a complex interplay between conduction system and LV muscle disease, applying ECG criteria to recognize mainly muscle disease (LVH) in those with established conduction disease (strict LBBB criteria) might lead to many false positivesas observed by the low positive likelihood ratios found in our study. Indeed, our results from the correlation coefficients between the ECG criteria and left ventricular mass support this hypothesis as well, where correlation coefficients were consistently weak/moderate for all studied ECG criteria.

Our findings also inform practice. The 2018 AHA/ ACCF/HRS guidelines recommend that patients diagnosed with new LBBB should undergo screening with echocardiogram [22]. However, the approach for patients at risk for LVH and a baseline echocardiogram without $\mathrm{LVH}$ is still uncertain. Because of the long waiting time for echocardiogram in low- and middle-income countries [23], alternatives for LVH assessment are needed, as LVH might influence treatment decisions [24]. ECGs can be performed at a low cost and repeated on a regular basis [23], helping clinicians to identify patients who have evolving changes and are at high risk of adverse outcomes earlier. This approach can shorten echocardiogram waiting times for those deemed high risk and create an earlier therapeutic window for intervention. Nevertheless, based on our findings, the ECG criteria we tested are not reliable to guide selective screening of patients for $\mathrm{LVH}$ when LBBB is present, and, therefore, routine assessment of LVH based on ECG criteria should not be performed.

\section{Study limitations}

This was a retrospective single-center study with inherent limitations that warrant acknowledgment. First, despite screening more than 4,000 patients, our final sample size is small, which mirrors the prevalence of LBBB. Second, we excluded patients with atrial fibrillation and other non-sinus rhythms to minimize differences between QRS voltage measurements and caution is needed when attempting to extrapolate our findings to these patients. Third, as our study was performed using a single ECG analysis, we have not evaluated if evolving changes in 


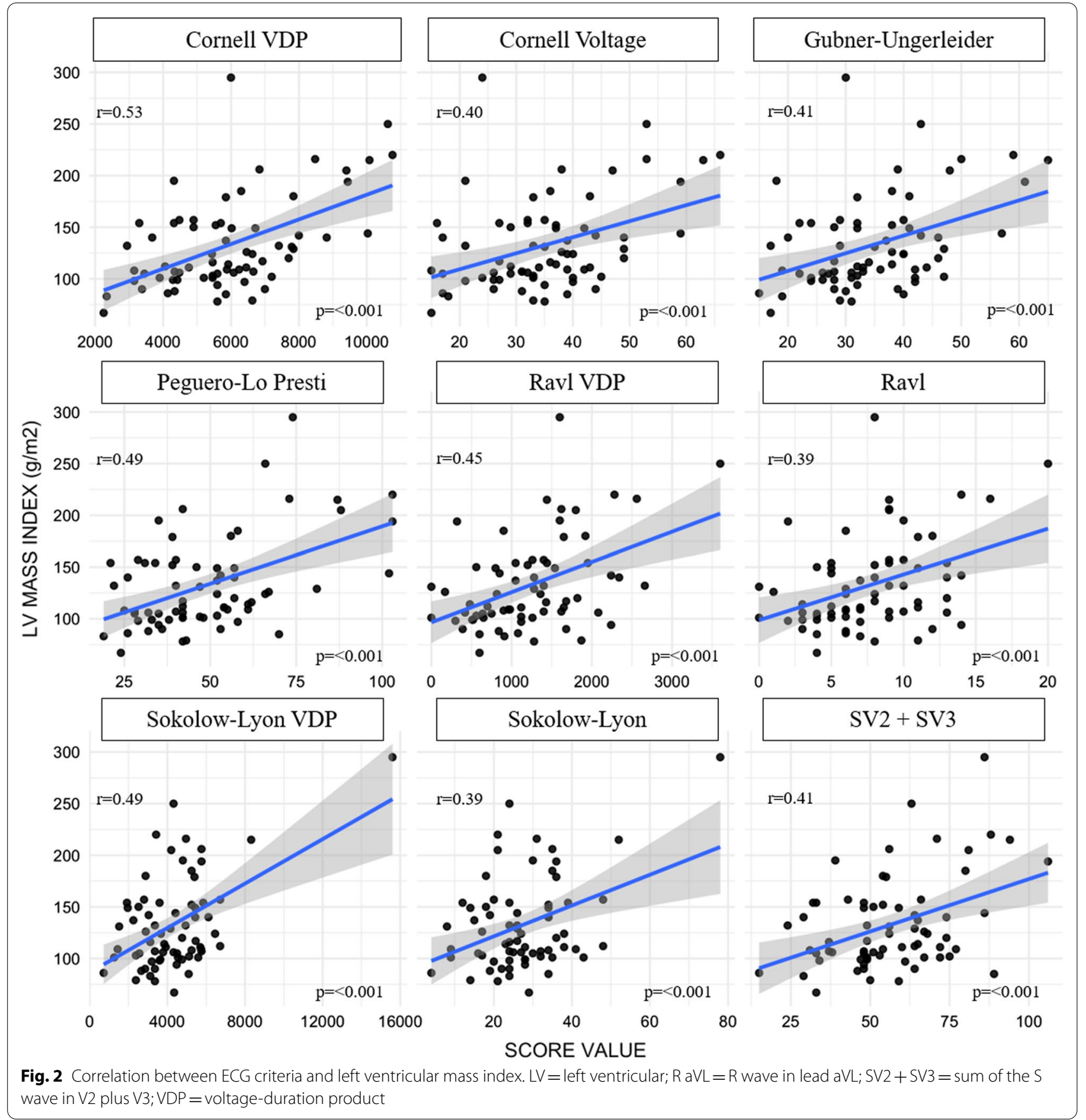

ECG criteria over time might have a role in the diagnosis or follow-up of ECG-based LVH. Fourth, our study did not address if ECG-based LVH (named electrical $\mathrm{LVH}$ ) might provide prognostic information even in the absence of LVH as assessed by echocardiogram (named anatomic LVH) in patients with LBBB, as long-term outcomes were not available [25]. Finally, our population is representative of a tertiary cardiovascular reference center, where there is a high burden of cardiovascular disease, and the generalization of our findings to primary and secondary care settings may be limited.

\section{Conclusion}

Our findings suggest no role for routine use of traditional LVH electrocardiographic criteria in patients with LBBB, neither for screening of LVH nor for guiding a selective approach to ordering echocardiograms. 


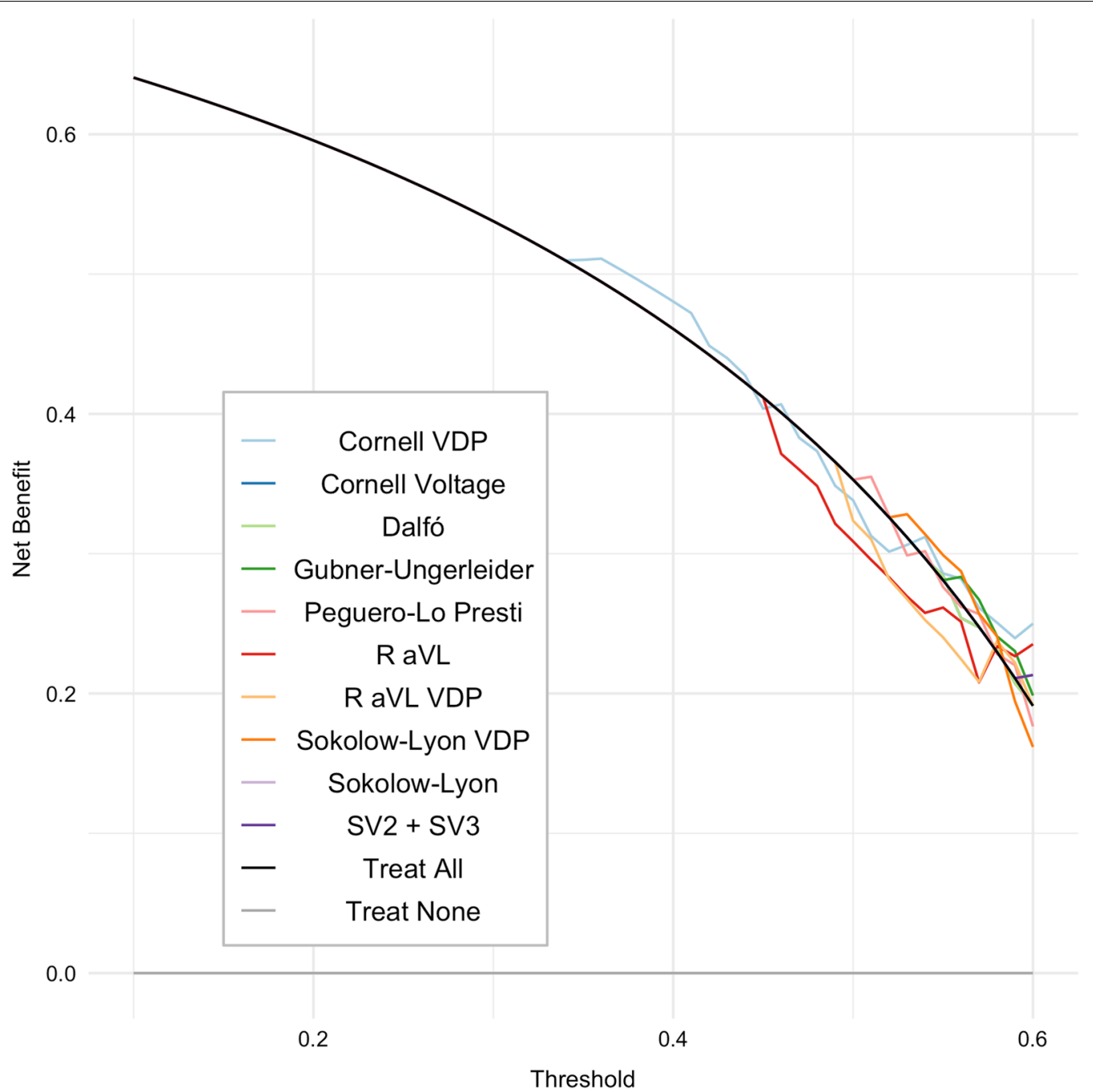

Fig. 3 Decision curve analysis for the ECG criteria. Decision curve analysis of the ECG criteria for the detection of left ventricular hypertrophy as assessed by the echocardiogram. For different risk thresholds for which the clinician would opt to order an echocardiogram, the net benefit of each ECG criteria is plotted compared against strategies of echocardiogram to all patients (black line) or none (grey line). Cl=Confidence Interval; R $\mathrm{aVL}=\mathrm{R}$ wave in lead $\mathrm{aVL} ; \mathrm{SV} 2+\mathrm{SV} 3=$ sum of the $\mathrm{S}$ wave in $\mathrm{V} 2$ plus $\mathrm{V} 3 ; \mathrm{VDP}=$ voltage-duration product

\section{Supplementary Information}

The online version contains supplementary material available at https://doi. org/10.1186/s12872-021-02332-8.

Additional file 1. Supplementary Tables S1-S3.

\section{Acknowledgements}

The authors thank Ms. Elisângela Alcântara for general assistance.

\section{Authors' contributions}

CAMT and NS planned the study and primarily wrote the manuscript. FLN did the primary statistical analysis and contributed to writing and editing. LCG and MEF contributed to methodology, writing and editing. EMHP and MF did data acquisition and contributed to writing and editing. CAP, LAH and WJF helped conceive the original idea of the study and supervised the findings of the work to the final written manuscript. All the authors reviewed and approved the final version of the manuscript.

\section{Funding}

None.

\section{Availability of data and materials}

The datasets generated and analyzed during the current study are available from the corresponding author on reasonable request.

\section{Declarations}

\section{Ethics approval and consent to participate}

The study was approved by the Ethics Committee of the Hospital das Clínicas, Medicine School, University of São Paulo, Brazil (Protocol Number 3.210.301, Project Number 08797119.1.0000.0068 on 03/20/2019) and the need for individual signed informed consent was waived. We declare that all methods were performed in accordance with relevant guidelines and regulations.

\section{Consent for publication}

Not applicable. 


\section{Competing interests}

Caio de Assis Moura Tavares: none; Nelson Samesima: none; Felippe Lazar Neto: none; Ludhmila Abrahão Hajjar: none; Lucas C. Godoy: none; Eduardo Messias Hirano Padrão: none; Mirella Facin: none; Wilson Jacob Filho: none; Michael E. Farkouh: research grants from Amgen, Novartis and Novo Nordisk; Carlos Alberto Pastore: none.

\section{Author details}

${ }^{1}$ Instituto do Coracao (InCor), Hospital das Clinicas HCFMUSP, Faculdade de Medicina, Universidade de Sao Paulo, Sao Paulo, Brazil. ${ }^{2}$ Peter Munk Cardiac Centre and Heart and Stroke/Richard Lewar Centre of Excellence in Cardiovascular Research, University of Toronto, Toronto, ON, Canada. ${ }^{3}$ Unidade de Eletrocardiografia, Instituto do Coracao, Hospital das Clínicas, Faculdade de Medicina, Universidade de Sao Paulo, Av. Dr Enéas de Carvalho Aguiar, 44, andar AB, Sao Paulo, SP 05403-900, Brazil.

Received: 17 May 2021 Accepted: 12 October 2021

Published online: 17 November 2021

\section{References}

1. Vakili BA, Okin PM, Devereux RB. Prognostic implications of left ventricular hypertrophy. Am Heart J. 2001;141(3):334-41.

2. Okin PM, Devereux RB, Jern S, Kjeldsen SE, Julius S, Nieminen MS, et al. Regression of electrocardiographic left ventricular hypertrophy during antihypertensive treatment and the prediction of major cardiovascular events. JAMA. 2004;292(19):2343-9.

3. Mathew J, Sleight P, Lonn E, Johnstone D, Pogue J, Yi Q, et al. Reduction of cardiovascular risk by regression of electrocardiographic markers of left ventricular hypertrophy by the angiotensin-converting enzyme inhibitor ramipril. Circulation. 2001;104(14):1615-21.

4. Williams B, Mancia G, Spiering W, Agabiti Rosei E, Azizi M, Burnier M, et al. 2018 ESC/ESH guidelines for the management of arterial hypertension. Eur Heart J. 2018:39(33):3021-104.

5. Hancock EW, Deal BJ, Mirvis DM, Okin P, Kligfield P, Gettes LS, et al. AHA/ ACCF/HRS recommendations for the standardization and interpretation of the electrocardiogram: part $\mathrm{V}$ : electrocardiogram changes associated with cardiac chamber hypertrophy: a scientific statement from the American Heart Association Electrocardiography and Arrhythmias Committee, Council on Clinical Cardiology; the American College of Cardiology Foundation; and the Heart Rhythm Society: endorsed by the International Society for Computerized Electrocardiology. Circulation. 2009;119(10):e251-61.

6. Rodriguez-Padial L, Rodriguez-Picon B, Jerez-Valero M, Casares-Medrano J, Akerstrom FO, Calderon A, et al. Diagnostic accuracy of computerassisted electrocardiography in the diagnosis of left ventricular hypertrophy in left bundle branch block. Rev Esp Cardiol (Engl Ed). 2012;65(1):38-46

7. Fragola PV, Autore C, Ruscitti G, Picelli A, Cannata D. Electrocardiographic diagnosis of left ventricular hypertrophy in the presence of left bundle branch block: a wasted effort. Int J Cardiol. 1990;28(2):215-21.

8. Strauss DG, Selvester RH, Wagner GS. Defining left bundle branch block in the era of cardiac resynchronization therapy. Am J Cardiol. 2011;107(6):927-34

9. Eriksson P, Hansson PO, Eriksson H, Dellborg M. Bundle-branch block in a general male population: the study of men born 1913. Circulation. 1998;98(22):2494-500.
10. Zannad F, Huvelle E, Dickstein K, van Veldhuisen DJ, Stellbrink C, Kober $\mathrm{L}$, et al. Left bundle branch block as a risk factor for progression to heart failure. Eur J Heart Fail. 2007:9(1):7-14.

11. Forouzanfar MH, Liu P, Roth GA, Ng M, Biryukov S, Marczak L, et al. Global burden of hypertension and systolic blood pressure of at least 110 to 115 mm Hg, 1990-2015. JAMA. 2017;317(2):165-82.

12. Tan NY, Witt CM, Oh JK, Cha YM. Left bundle branch block: current and future perspectives. Circ Arrhythm Electrophysiol. 2020;13(4):e008239.

13. Vickers AJ, Elkin EB. Decision curve analysis: a novel method for evaluating prediction models. Med Decis Making. 2006;26(6):565-74.

14. Risum N, Strauss D, Sogaard P, Loring Z, Hansen TF, Bruun NE, et al. Left bundle-branch block: the relationship between electrocardiogram electrical activation and echocardiography mechanical contraction. Am Heart J. 2013;166(2):340-8.

15. Baranowski R, Malek L, Prokopowicz D, Spiewak M, Misko J. Electrocardiographic diagnosis of the left ventricular hypertrophy in patients with left bundle branch block: is it necessary to verify old criteria? Cardiol J. 2012;19(6):591-6.

16. Li ZB, Wachtell K, Okin PM, Gerdts E, Liu JE, Nieminen MS, et al. Association of left bundle branch block with left ventricular structure and function in hypertensive patients with left ventricular hypertrophy: the LIFE study. J Hum Hypertens. 2004;18(6):397-402.

17. Kafka H, Burggraf GW, Milliken JA. Electrocardiographic diagnosis of left ventricular hypertrophy in the presence of left bundle branch block: an echocardiographic study. Am J Cardiol. 1985;55(1):103-6.

18. Klein RC, Vera Z, DeMaria AN, Mason DT. Electrocardiographic diagnosis of left ventricular hypertrophy in the presence of left bundle branch block. Am Heart J. 1984;108(3 Pt 1):502-6.

19. Noble LM, Humphrey SB, Monaghan GB. Left ventricular hypertrophy in left bundle branch block. J Electrocardiol. 1984;17(2):157-60.

20. Cokkinos DV, Demopoulos JN, Heimonas ET, Mallios C, Papazoglou N, Vorides EM. Electrocardiographic criteria of left ventricular hypertrophy in left bundle-branch block. Br Heart J. 1978;40(3):320-4.

21. Vandenberg BF, Romhilt DW. Electrocardiographic diagnosis of left ventricular hypertrophy in the presence of bundle branch block. Am Heart J. 1991;122(3 Pt 1):818-22.

22. Kusumoto FM, Schoenfeld MH, Barrett C, Edgerton JR, Ellenbogen KA, Gold MR, et al. 2018 ACC/AHA/HRS guideline on the evaluation and management of patients with bradycardia and cardiac conduction delay: executive summary: a report of the American College of Cardiology/ American Heart Association Task Force on Clinical Practice Guidelines, and the Heart Rhythm Society. J Am Coll Cardiol. 2019;74(7):932-87.

23. Nascimento BR, Beaton AZ, Nunes MCP, Tompsett AR, Oliveira KKB, Diamantino $A C$, et al. Integration of echocardiographic screening by non-physicians with remote reading in primary care. Heart. 2019;105(4):283-90.

24. Soliman EZ, Ambrosius WT, Cushman WC, Zhang ZM, Bates JT, Neyra JA, et al. Effect of intensive blood pressure lowering on left ventricular hypertrophy in patients with hypertension: SPRINT (Systolic Blood Pressure Intervention Trial). Circulation. 2017;136(5):440-50.

25. Aro AL, Chugh SS. Clinical diagnosis of electrical versus anatomic left ventricular hypertrophy: prognostic and therapeutic implications. Circ Arrhythm Electrophysiol. 2016;9(4):e003629.

\section{Publisher's Note}

Springer Nature remains neutral with regard to jurisdictional claims in published maps and institutional affiliations. 